\title{
Vertical growth in mono-and dizygotic twins: a longitudinal cephalometric cohort study
}

Hersberger-Zurfluh, Monika A ; Papageorgiou, Spyridon N ; Motro, Melih ; Kantarci, Alpdogan ; Will, Leslie A ; Eliades, Theodore

Abstract: Objective: The aims of this longitudinal analysis of untreated monozygotic and dizygotic twins were to investigate vertical changes of the craniofacial structures during growth, to determine the concordance between genetically twins and to assess the genetic component for the various aspects of vertical growth. Settings and sample population: The sample consisted of 34 pairs of untreated monozygotic twins (23 male, 11 female) and 30 untreated dizygotic siblings of multiple birth ( 8 male, 8 female and 14 mixed) from the Forsyth Moorrees Twin Study (1959-1975); lateral cephalograms taken from 6 to 18 years of age were analysed at 3-year intervals. Materials and methods: Cephalograms were traced, and longitudinal changes between twins in six angular and proportional vertical cephalometric variables (SN-NL, ML-NL, SN-ML, y-axis, PFH/AFH and LAFH/AFH) were analysed with intraclass correlation coefficients and linear regression modelling. Results: The concordance between monozygotic/dizygotic twins at 18 years of age was moderate to high with intraclass correlation coefficient values between 0.51 and 0.66 . Additionally, sex differences in concordance at 18 years of age were found for three variables. High heritability (66\%-79\%) was observed for 5 of the 6 variables (LAFH/AFH, ML-NL, y-axis, SN-ML, $\mathrm{PFH} / \mathrm{AFH}$ ), while SN-NL showed limited heritability (34\%). Conclusions: Although monozygotic/dizygotic twins share at least part of their genetic material, differences in the vertical dimension were found. This supports the complex developmental mechanism of the human face and the varying influence of genetic and environmental factors. Keywords: cephalometrics; cohort study; craniofacial growth; genetics; mandibular growth; twins.

DOI: https://doi.org/10.1111/ocr.12358

Posted at the Zurich Open Repository and Archive, University of Zurich

ZORA URL: https://doi.org/10.5167/uzh-186063

Journal Article

Accepted Version

Originally published at:

Hersberger-Zurfluh, Monika A; Papageorgiou, Spyridon N; Motro, Melih; Kantarci, Alpdogan; Will, Leslie A; Eliades, Theodore (2020). Vertical growth in mono-and dizygotic twins: a longitudinal cephalometric cohort study. Orthodontics craniofacial research, 23(2):192-201.

DOI: https://doi.org/10.1111/ocr.12358 


\section{Vertical growth in mono- and dizygotic twins: A longitudinal cephalometric cohort study}

Monika A. Hersberger-Zurfluh ${ }^{1,2}$ | Spyridon N. Papageorgiou ${ }^{1}$ | Melih Motro² | Alpdogan Kantarci ${ }^{3}$ | Leslie A. Will ${ }^{3} \mid$ Theodore Eliades ${ }^{1}$

${ }^{1}$ Clinic of Orthodontics and Pediatric Dentistry, Center of Dental Medicine, University of Zurich, Zurich, Switzerland

${ }^{2}$ Department of Orthodontics and Dentofacial Orthopedics, Goldman School of Dental Medicine, Boston University, Boston, Mass.

${ }^{3}$ Forsyth Institute, Cambridge, Mass; Goldman School of Dental Medicine, Boston University, Boston, Mass.

\section{Correspondence}

Theodore Eliades, Clinic of Orthodontics and Pediatric Dentistry, Center of Dental Medicine, University of Zurich, Plattenstrasse 11, Zurich 8032, Switzerland. E-mail: theodore.eliades@zzm.uzh.ch.

\section{Short title}

Vertical growth in twins.

\section{ORCIDs}

Monika A. Hersberger-Zurfluh: 0000-0001-5366-6066

Spyridon N. Papageorgiou: 0000-0003-1968-3326

Melih Motro: 0000-0002-6142-7804

Alpdogan Kantarci: 0000-0002-2679-9100

Leslie A. Will: 0000-0001-7456-136X

Theodore Eliades: 0000-0003-2313-4979 


\section{Acknowledgements}

None.

\section{Conflict of interest}

None. All authors declare that there are no conflicts of interest.

\section{Funding information}

No funding. 


\section{Structured Abstract}

Objective: The aims of this longitudinal analysis of untreated monozygotic and dizygotic twins were to investigate vertical changes of the craniofacial structures during growth, to determine the concordance between genetically twins, and to assess the genetic component for the various aspects of vertical growth.

Settings and Sample Population: The sample consisted of 34 pairs of untreated monozygotic twins (23 male, 11 female) and 30 untreated dizygotic siblings of multiple birth (8 male, 8 female, and 14 mixed) from the Forsyth Moorrees Twin Study (1959-1975); lateral cephalograms taken from 6 to 18 years of age were analyzed at 3-year intervals.

Materials and Methods: Cephalograms were traced, and longitudinal changes between twins in six angular and proportional vertical cephalometric variables (SN-NL, ML-NL, SN-ML, y-axis, PFH/AFH, and $\mathrm{LAFH} / \mathrm{AFH}$ ) were analyzed with intraclass correlation coefficients and linear regression modelling.

Results: The concordance between monozygotic/dizygotic twins at 18 years of age was moderate to high with intraclass correlation coefficients values between 0.51 and 0.66 . Additionally, sex differences in concordance at 18 years of age were found for three variables. High heritability (66\%-79\%) was observed for 5 of the 6 variables (LAFH/AFH, ML-NL, y-axis, SN-ML, PFH/AFH), while SN-NL showed limited heritability (34\%).

Conclusions: Although monozygotic/dizygotic twins share at least part of their genetic material, differences in the vertical dimension were found. This supports the complex developmental mechanism of the human face and the varying influence of genetic and environmental factors.

\section{KEYWORDS}

Craniofacial growth, twins, mandibular growth, cephalometrics, cohort study, genetics 


\section{1 | INTRODUCTION}

It is generally accepted that physical attractiveness is related to attractiveness of the facial profile, which theoretically at least can be positively influenced by orthodontic treatment. ${ }^{1}$ This has been founded on the notion that the shape and size of the craniofacial structures might be affected by both genetic and environmental factors. ${ }^{2}$ Growth modification through orthopedic treatment and whether this can have an effect of clinically relevant magnitude has been the subject of much controversy during the last decades ${ }^{3-5}$ and many researchers believe that growth is mostly under genetic influence. ${ }^{6-7}$ Objective growth assessment has been traditionally performed in the field of orthodontics through analysis of lateral cephalograms, which can be also used to examine the genetic contribution on the growth of skeletal and dental structures by comparing cephalograms of parents and their offspring. ${ }^{8}$

Evidence of heritability in the antero-posterior and vertical dimensions has been reported, ${ }^{9,10}$ while

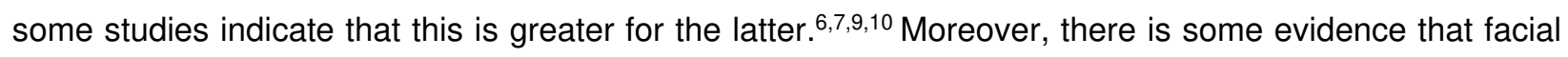
similarity between twins may decrease with age as growth-related changes in most facial variables are apparently under relatively weak genetic control. ${ }^{11,12}$ However, other researchers reported that the changes in anterior face height and the antero-posterior position of the mandible are strongly influenced by genetic factors. ${ }^{13}$ According to Manfredi et al. anterior vertical parameters show greater heritability than posterior ones, while the shape of the mandible shows greater heritability than its size. ${ }^{14}$ The latter finding was confirmed by recent evidence indicating that the angular measurements representing mandibular skeletal morphology (mandibular form) had greater genetic determination than its absolute size. ${ }^{15}$

On the other side, it is generally accepted that numerous polygenic craniofacial components are susceptible to environmental modification, which complicates their assessment with conventional methods. ${ }^{16}$ The twin study method can provide an excellent opportunity to analyze such traits, as it enables assessment of genetic contributions on craniofacial growth by reducing or even minimizing the environmental effect. Therefore, cephalometric studies of monozygotic (MZ) and dizygotic (DZ) twins can be viewed as powerful instruments not only in orthodontic diagnosis and treatment planning, but also in growth prediction and estimation of treatment prognosis. Classical methods of analysis have been based on comparisons of the differences within pairs of identical or fraternal twins, whereas the extent of the concordance or difference respectively being taken as an indication of the relative genetic contribution. ${ }^{17,18}$ 
However, only few studies up to now have assessed genetic components of craniofacial structures by following longitudinally $M Z$ and $D Z$ twins during the growth process. ${ }^{11,12,18}$

To our knowledge there is no longitudinal investigation that quantifies genetic and environmental influences on vertical facial growth of $M Z$ and $D Z$ twins. Consequently, the purpose of this retrospective longitudinal cephalometric cohort study was to determine the genetic and environmental influence on vertical skeletal growth during childhood, adolescent, and early adult growth of untreated MZ and DZ twins.

\section{2 | MATERIAL AND METHODS}

\section{1 | Study sample}

The twins participated in this retrospective cohort study were recruited from the Forsyth Moorrees Twin Study sample that was gathered from 1959-1975 at the Forsyth Infirmary for Children in Boston. The protocol of the study has been accepted by the Institutional Review Board approval (Boston University \#H31945). This registry includes approximately 500 twin pairs who registered and came for annual records. Zygosity determination was determined by serologic testing of 29 factors supplemented by phenotypic similarity (tooth morphology, hair and eye color, freckles, ear attachment, and finger morphology). All twins are Caucasian and have no previous history of orthodontic treatment. Eligible patients for this investigation were those with (1) no history of orthodontic treatment, craniofacial anomalies, or chronic systemic disease and (2) available lateral cephalograms in good quality. All patients were measured at approximately the same time points every 3 years from middle childhood to early adulthood: T1 at 6 years, T2 at 9 years, T3 at 12 years, T4 at 15 years, and T5 at 18 years of age.

\section{2 | Cephalometric measurements}

The lateral cephalograms were taken in a standardized position in centric occlusion and a cephalostat (copy of the Broadbent cephalometer) was used to maintain the subject's head in a constant relationship to the device. The focus-coronal plane distance was $9 \mathrm{~cm}$ and the film-coronal plane distance was $150 \mathrm{~cm}$, which resulted to a constant magnification factor of $6 \%$. The subjects were asked to refrain from swallowing during 
the radiological examination, with tongue posture subsequently assessed on the cephalograms to ascertain that no children swallowed during the radiographic examination.

After anonymization of all documents with a unique code, radiographs were traced by two persons (MZ: MHZ, DZ: SNP) using the Viewbox imaging software version 4.0 (dhal, Kifissia, Greece). Six widely used facial vertical measurements were made on the films of 64 pairs/triplets/quadruples of siblings at five time points (T1-T5), including SN-NL, ML-NL, SN-ML, Y-axis, PFH-AFH, LAFH-AFH (Fig 1).

\section{3 | Statistical analysis}

Sample size calculation was performed a priori for the first study in this project, which aimed to find a clinically significant concordance in facial convexity between solely MZ twins with the Intraclass Correlation Coefficient (ICC) Hersberger et al., 2018]. Based on previous data ${ }^{19}$ we assumed an ICC $=0.50$ between twins of each pair at T5 and aimed to find a minimal statistically significant difference of half a Standard Deviation (SD) with a paired t-test. Assuming a change of $2^{\circ}$ in facial convexity, with a SD of $4^{\circ}$ for $T 5$ from a similar study, ${ }^{20} \alpha=5 \%$, and power $=80 \%$ it was calculated that a sample of 28 twin pairs would be needed to provide adequate power, to which 5 more twin pairs were added to account for any missing patient files. The sample of the present study was doubled by adding the DZ twins, and therefore, was deemed to be adequately powered.

Descriptive statistics (means and SD) were calculated for all variables. We conducted mixed-effects linear regressions to calculate if sex and zygosity were associated with vertical skeletal growth, while accounting for repeated measurements (time-points T1 through T5) per patient and clustering within families. The regression results were expressed as unstandardized regression coefficients (b) and their $95 \%$ Cls. Separate interaction terms of time (T1-T5) with either sex or zygosity were added in preliminary models and kept in the final model only if statistically significant at $5 \%$. For variables with a significant time interaction with either sex or zygosity, stratified models were also provided.

Additionally, for each cephalometric variable the concordance of MZ/DZ twins after growth cessation (T5 - 18 years) was assessed by calculating ICCs from random-effects modelling (ranging from 0 to 1 to denote the amount of variance explained from the twins' clustering) and their $95 \%$ Cls. The heritability of each cephalometric variable was calculated according to the formula of Jacquard:21 
$\frac{\text { concordance }(M Z)-\text { concordance }(D Z)}{1-\text { concordance }(D Z)}$. As many dropouts were seen at T5 (18 years), a sensitivity analysis was also conducted at T4 (15 years) to evaluate if these dropouts could influence the results.

All analyses were run in Stata SE 14.0 (StataCorp LP, College Station, TX) with an unadjusted $\alpha$ of $5 \%$, since the study's scope is based on descriptive analysis of concordance and associated factors.

\section{4 | Method error}

Intra-observer method error was assessed using coefficient of reliability and the Bland-Altman limits of agreement. The reliability of the method was tested by tracing and measuring 50 selected lateral cephalograms twice from the same assessor (MZ: MHZ; DZ: SP) with a one-month time interval.

\section{3 | RESULTS}

A total of 131 eligible siblings divided in 34 families of $M Z$ twins and 30 families of $D Z$ siblings of multiple births (28 families of twins, one family of triplets, and one family of quadruplets) were included in the study. Of the $34 \mathrm{MZ}$ twin pairs, 23 pairs (68\%) were male and 11 pairs (32\%) were female. Of the $30 \mathrm{DZ}$ sibling families, $8(27 \%)$ twin pairs were male, $8(27 \%)$ twin pairs were female, and $14(47 \%)$ families (12 of twin pairs, 1 of triplets, and 1 of quadruplets) were mixed male/female. At T1 103 participants, at T2 130 participants, at T3 131 participants, at T4 128 participants, and at T5 85 participants were included in the follow-up. The descriptive statistics about the average values and the mean differences between $\mathrm{MZ}$ and DZ twins for each variable at each time point are given in Table 1.

The regression modeling of the variations of the six cephalometric measurements showed some clear patterns during growth (Figures 2; Table 2). Three variables tended to decrease from T1 during growth (ML-NL, SN-ML, and LAFH/AFH), one variable increased during growth (PFH/AFH), while two variables remained practically stable throughout T1-T5 (SN-NL and y-axis). Consistent sex differences throughout the growth period were found for two variables (SN-NL and y-axis). Male participants consistently had a significantly smaller $\mathrm{SN}-\mathrm{NL}$ angle $\left(\mathrm{b}=-1.7^{\circ} ; 95 \% \mathrm{Cl}=-2.5\right.$ to $\left.-0.9^{\circ} ; \mathrm{P}<0.001\right)$ and smaller $\mathrm{y}$-axis $\left(\mathrm{b}=-1.4^{\circ}\right.$; $95 \% \mathrm{Cl}=-2.5^{\circ}$ to $\left.-0.3^{\circ} ; \mathrm{P}=0.01\right)$ than female participants throughout the growth period (T1-T5). Additionally, consistent differences between $\mathrm{MZ}$ and $\mathrm{DZ}$ siblings during the growth period were seen in two variables 
(SN-NL and LAFH/AFH). DZ siblings had consistently smaller SN-NL angle (b =-0.9 $; 95 \% \mathrm{Cl}=-1.8$ to $-0.1^{\circ}$; $\mathrm{P}=0.03)$ and lower $\mathrm{LAFH} / \mathrm{AFH}$ ratio $(\mathrm{b}=-1.5 \% ; 95 \% \mathrm{Cl}=-2.2$ to $-0.8 \% ; \mathrm{P}<0.001)$ compared to $\mathrm{MZ}$ twins.

Moreover, significant interaction for gender with time were seen for two variables (SN-ML and $\mathrm{PFH} / \mathrm{AFH}$; Table 2), which indicate that male and female participants might show different growth patterns. This was analyzed with sex-stratified models in Table S1. The results indicated that male participants showed a greater reduction in the SN-ML angle and a greater increase in the PFH/AFH ratio than female participants. Also, a significant interaction of zygosity with time was seen for ML-NL (Table 2), which was further analyzed in Table S2. This showed that DZ siblings showed a greater decrease from T1 in the ML$\mathrm{NL}$ angle compared to $\mathrm{MZ}$ twins.

Finally, the concordance between MZ/DZ twins at 18 years (T5) was assessed (Table 5) and varied among the included variables between 0.51 and 0.66 (i.e. twins' similarity varying between $51 \%$ and $66 \%$ ). The contribution of sex on the concordance between twins were seen for three variables, where female twins were more concordant in the SN-NL angle than male twins, while the opposite was seen for ML-NL and LAFH/AFH. As far as heritability is concerned, the LAFH/AFH was the most heritable variable (79\%), followed by ML-NL (72\%), y-axis (72\%), SN-ML (67\%), PFH/AFH (66\%), and SN-NL (34\%). These results were confirmed by the sensitivity analysis using data from T4 (15 years), which showed homogeneity (Table S3), even though the ICCs were lower than T5 probably due to residual growth.

Finally, the analysis of the repeated measurements showed high reliability and small limits of agreement in all instances, which supported the robustness of the method (Table S4).

\section{4 | DISCUSSION}

This is to our knowledge the first study to assess in a longitudinal method the genetic and environmental contributions on the vertical growth of twins throughout the growth period. For this study, 34 families of MZ twins and 30 families of $D Z$ siblings were analyzed from 6 to 18 years of age in terms of 6 vertical measurements on lateral cephalograms.

According to the results of the current study, a complex craniofacial variation pattern throughout growth could be seen. One variable showed a constant increase during growth (PFH/AFH), three variables (ML-NL, SN-ML, and LAFH/AFH) decreased during growth, while two variables remained the relatively 
stable during growth (SN-NL and y-axis) (Table 1). Growth changes in these variables resulted in a reduced inclination of the mandibular corpus to the cranial or nasal plane (reduced ML-NL and SN-ML angles), a reduced lower anterior face height relative to the total anterior face height (reduced LAFH/AFH angle), increased posterior vertical growth (increased PFH/AFH angle) and relative stable inclination of the maxilla (SN-NL) or mandibular growth direction (y-axis). Overall, these findings are in accordance with previous growth studies. ${ }^{22-23}$

Only two variables (SN-NL and Y-axis) showed consistent sex differences throughout the growth period (Table 2), which indicated that boys and girls differed in the absolute values (with boys having smaller inclination of the nasal plane and more anterior mandibular growth than girls), but showed growth of same direction and magnitude within the observation period. Also, a significant interaction for sex and time could be found for mandibular inclination and posterior to anterior face height (SN-ML and PFH/AFH), which give indicate that boys and girls grow differently (Table S1). Interestingly, the boys showed a greater increase in the PFH/AFH ratio (greater posterior vertical development) and a greater reduction in the SN-ML angle (greater anterior rotation of the mandibular corpus) than female participants, which is again in concordance with current knowledge, but is the first time that this is confirmed in a longitudinal study of MZ/DZ twins.

As far as heritability of the craniofacial growth is concerned, Harris et al. ${ }^{24}$ reported that the heritability of cephalometric variable increases between 4 and 20 years of age. Consequently, comparisons of hereditary components in male and female participants should be ideally performed in the postadolescent period, when craniofacial growth is nearly completed. It has been known for some time, that craniofacial growth cessation takes place approximately two years later for boys than for girls,,$^{25,26}$ but we should also consider that chronological age is not always a reliable indicator for this. Consequently, the concordance between MZ/DZ twins for each radiographic variable was primarily evaluated at T5 when facial growth was mainly assumed to be completed. According to Bjork ${ }^{27}$ the remaining skeletal growth of the mandible two years after growth spurt is negligible from a clinical point of view. The results of this study indicated that considerable concordance existed for all assessed variables (ICCs $>0.50$; Table 5), which meant that the twins assessed showed similar vertical relationships. This is logical, since these twins share both (at least) part of their genetic material and at least some common environmental influences. However, the heritability estimates show a different picture (Table 5). According to these, very high heritability values 
were found for LAFH/AFH, ML-NL y- axis, SN-ML, and PFH/AFH (66\%-79\%), which indicate a strong genetic component. Previous data have highlighted a strong genetic control on some variables assessed in this study like $\mathrm{LAFH} / \mathrm{AFH}, \mathrm{y}$-axis, and the FH-ML (which is similar to the SN-ML variable used in this study). ${ }^{14}$ The current study also added the variables ML-NL and PFH/AFH as novel aspects of the vertical dimension that are under strong genetic influence. In contrast, the SN-NL angle showed very low heritability (34\%), which agrees with previous data. ${ }^{14}$ Additionally, sex variations were found for the heritability of SN$\mathrm{NL}, \mathrm{ML}-\mathrm{NL}$, and LAFH/AFH (Table 5). For the SN-NL angle, female twins were more consistent than male ones, while for ML-NL and LAFH/AFH the opposite was observed. However, all the twins lived in the same families and conditions, and therefore, the differences in environmental influence can be expected to be small. ${ }^{28}$ Consequently, the explanation for this could lie in a stronger genetic component for these traits in female or male twins respectively.

Interestingly the overall concordance between twins at the end of the study period was quite similar, ranging from $51 \%$ for $\mathrm{LAFH} / \mathrm{AFH}$ to $66 \%$ for $\mathrm{PFH} / \mathrm{AFH}$ (Table 5 ). This study extends the previous evidence for heritability to lateral cephalometric variables, which have demonstrated a high concordance between monozygotic and dizygotic twins. ${ }^{14}$ With the exception of the SN-NL angle (65\%), all other measured values within monozygotic twins were above $83 \%$, which confirms the zygosity assessment, based on anthropometric diagnosis only. Since identical twins share $100 \%$ their genome, it might be assumed that high concordance rates for specific measurements indicate that this trait is determined to a higher degree genetically and less by environmental factors. However, this fact might indicate that room for individual variation exists even between genetically identical twins, and environmental factors might influence the development of this particular angle (NS-NL). This finding agrees with previous studies which demonstrate that heritability estimates for dentoalveolar variables were considerably lower than for skeletal traits. ${ }^{8,29,30}$ From clinical research it is well known, that environmental factors like tongue, lips and cheeks, oral muscles, and certain functions (breathing and mastication) as well as body posture play a central role in the development of occlusion. ${ }^{2,31,32}$ On that basis, it is hardly surprising that SN-NL was with $34 \%$ the least heritable variable at $\mathrm{T} 5$, since exactly these factors could contribute to an alteration of this angle. The heritability in our study was highest with $79 \%$ for the ratio of lower anterior face height to anterior face height ( $\mathrm{LAFH} / \mathrm{AFH})$. This finding is according to pertinent literature, which showed that heritability seems to have 
more influence on anterior vertical parameters than posterior. ${ }^{14,15}$ Furthermore, it seems that the lower third of the face is under strong genetic control. ${ }^{11,33,34}$ The remaining values in the present study were for $Y$-axis and ML-NL: $72 \%$, SN-ML: $67 \%$ and PFH/AFH: $66 \%$. This is on par with former studies on siblings that indicated that the heritability of skeletal craniofacial variables increases with age. ${ }^{24}$ Previous studies on several skeletal cephalometric parameters indicated high heritability, ${ }^{35}$ with higher heritability values among vertical, compared with horizontal variables; $9,36,37$ however, Sidlauskas et al. ${ }^{15}$ stated that horizontal linear variables were more genetically determined than vertical variables.

Despite the fact that the included twins had no craniofacial anomalies and systemic diseases, other factors such as habits, allergies or airway disorders could have been present and influenced their craniofacial growth. Because there was no access to medical records so many years after the sample was gathered, the presence or absence of the mentioned conditions could not be investigated. We have also to point out, that any variation measured during the study period is a sum of growth, environmental impacts, and random error. Furthermore, low-quality or missing lateral cephalograms at certain time points led to a subsequent loss of power through sample reduction. Additionally, all included twin pairs were Caucasians, which might impede a generalization of the findings to other populations.

As far as the analysis of serial lateral cephalometric radiographs is concerned, common measurements from widely employed analyses were employed in the present study, like SN-NL, ML-NL, SN-ML, Y-axis, PFH/AFH, and LAFH/AFH. Alternatively, a structural superimposition method could have been employed in order to quantify longitudinally displacements of specific points in a Cartesian $x-, y-$, and z-axis. However, high-quality films are necessary for this ${ }^{38}$ particularly with regard to optimal contrast and density, ${ }^{39}$ which limits this method's application. This is especially the case for historical studies such as this one, where radiographs from the 1950s-80s are used that lack the clarity of more recent radiographs. Additionally, several different structural superimposition methods have been proposed with many studies reporting conflicting results about their relative strengths and weaknesses. ${ }^{38-42}$ Furthermore, some studies have demonstrated specific inaccuracies of superimposition methods, ${ }^{43,44}$ while other studies ${ }^{42,45}$ suggest the use of multiple superimposition methods for optimum results, which might be time-consuming. Finally, some limitations of both conventional cephalometric analyses and structural superimposition changes could have been ameliorated with the use of more sophisticated techniques like geometric morphometrics. ${ }^{46}$ 
The ability to evaluate and predict growth lies at the very heart of orthodontics and dentofacial orthopedics and is of upmost importance for adequate treatment planning and successful treatment outcome. It is well known that both environmental and genetic factors can be the cause of skeletal anomalies. However, apart from limited but definitive knowledge on the genetics behind the shape and size of the mandible,${ }^{6,7}$ evidence about the heritability of malocclusions remains to that day inconsistent and is not clearly understood. ${ }^{47}$ But the genetic source of a skeletal anomaly should be considered during the diagnosis and the treatment plan should be performed accordingly.

For many decades, the classical twin study model has served as a powerful instrument in assessing the relative contribution of genetic and environmental factors. ${ }^{48}$ Therefore, studies with twin pairs can provide some important information concerning the role of genes and environment on skeletal phenotypic difference.

Among the strengths of the present study can be considered (a) the inclusion of both MZ and DZ twins that enable a more accurate partitioning of the genetic and environmental component of craniofacial variation and (b) the study's longitudinal follow-up that covers the greatest part of the adolescent and early adult growth period. Nevertheless, this is a purely clinical / radiographic study, and genome-wide association studies are needed to definitely identify the exact involvement of any genes in craniofacial growth. Until such data are available, the present study indicates that the different vertical components of the craniofacial complex are under considerable genetic control with high heritability (especially LAFH/AFH ratio, Y-axis, and ML-NL). Therapeutic approaches can only influence the basic growth pattern within the individual biological limits, and the environmental contribution on craniofacial variability should not be ignored. Since half of the examined variables (LAFH/AFH ratio, Y-axis, ML-NL) demonstrated high heritability, they can be used as predictors of unfavorable growth. Finally, no post hoc sample size calculation was done for this study, which is an extension of a previous study on MZ twins. ${ }^{12}$ As however the first study included a sample size calculation and the current study simply doubled the originally adequately powered sample, we do believe that this study is also adequately powered.

\section{5 | CONCLUSION}


This longitudinal study on untreated monozygotic / dizygotic twins through the growth period indicated the following:

1. The vertical dimension of the facial profile develops in a complex way with some variables increasing during growth, others reducing during growth, and others remaining stable.

2. Considerable differences in the vertical variation of the face were seen according to the sex and zygosity of the twins, highlighting genetic and environmental influences, respectively.

3. Concordance between siblings for all assessed vertical measurements was low to moderate for dizygotic twins (19\%-56\%) and high for monozygotic twins (65\%-85\%).

4. High heritability (66\%-79\%) was found for cephalometric variables pertaining to the inclination of the mandibular corpus, the growth direction, and the anterior/posterior face height.

5. The inclination of the maxilla on the other side showed limited heritability (34\%). 


\section{REFERENCES}

1. Pace M, Cioffi I, D'antò V, Valletta A, Valletta R, Amato M. Facial attractiveness of skeletal class I and class II malocclusion as perceived by laypeople, patients and clinicians. Minerva Stomatol. 2018;67:77-85.

2. Moss ML, Salentijn L. The primary role of functional matrices in facial growth. Am J Orthod. 1969;55:566-577.

3. Gianelly AA. One-phase versus two-phase treatment. Am J Orthod Dentofacial Orthop. 1995;108:556-559.

4. Chen JY, Will LA, Niederman R. Analysis of efficacy of functional appliances on mandibular growth. Am J Orthod Dentofacial Orthop. 2002;122:470-476.

5. De Clerck HJ, Proffit WR. Growth modification of the face: A current perspective with emphasis on Class III treatment. Am J Orthod Dentofacial Orthop. 2015;148:37-46.

6. Yamaguchi T, Park SB, Narita A, Maki K, Inoue I. Genome-wide linkage analysis of mandibular prognathism in Korean and Japanese patients. J Dent Res. 2005;84:255-259.

7. Li Q, Zhang F, Li X, Chen F. Genome scan for locus involved in mandibular prognathism in pedigrees from China. PLoS One 2010;5.

8. Nakasima A, Ichinose M, Nakata S, Takahama Y. Hereditary factors in the craniofacial morphology of Angle's Class II and Class III malocclusions. Am J Orthod. 1982;82:150156.

9. Hunter WS. A study of the inheritance of craniofacial characteristics as seen in lateral cephalograms of 72 like-sexed twins. Trans Fur Orthod Soc. 1965;59:70.

10. Lundström A, McWilliam JJ. A comparison of vertical and horizontal cephalometric variables with regard to heritability. Eur J Orthod. 1987;9:104-108.

11. Dudas M, Sassouni V. The hereditary components of mandibular growth, a longitudinal twin study. Angle Orthod. 1973;43:314-322. 
12. Hersberger-Zurfluh MA, Papageorgiou SN, Motro M, Kantarci A, Will LA, Eliades T. Facial soft tissue growth in identical twins. Am J Orthod Dentofacial Orthop. 2018;154:683-692.

13. Townsend G, Richards L. Twins and twinning, dentists and dentistry. Aust Dent J. 1990;35:317-327.

14. Manfredi C, Martina R, Grossi GB, Giuliani M. Heritability of 39 orthodontic cephalometric parameters on MZ, DZ twins and MN-paired singletons. Am J Orthod Dentofacial Orthop. 1997;111:44-51.

15. Šidlauskas M, Šalomskienè L, Andriuškevičiūtė I, et al. Heritability of mandibular cephalometric variables in twins with completed craniofacial growth. Eur J Orthod. 2016;38:493-502.

16. van der Linden FP. Genetic and environmental factors in dentofacial morphology. Am J Orthod. 1966;52:576-83.

17. Lundström A. Nature versus nurture in dento-facial variation. Eur J Orthod. 1984;6:77-91.

18. Peng J, Deng H, Cao C, Ishikawa M. Craniofacial morphology in Chinese femaletwins: a semi-longitudinal cephalometric study. Eur J Orthod. 2005;27:556-561.

19. Jorde LB, Carey JC, Bamshad MJ. Medical genetics. 4th ed. Philadelphia: Elsevier; 2009.

20. Bergman RT, Waschak J, Borzabadi-Farahani A, Murphy NC. Longitudinal study of cephalometric soft tissue profile traits between the ages of 6 and 18 years. Angle Orthod. $2014 ; 84: 48-55$.

21. Jacquard A. Heritability: one word, three concepts. Biometrics. 1983;39:465-477.

22. Björk A, Skieller V. Normal and abnormal growth of the mandible. A synthesis longitudinal cephalometric implant studies over a period of 25 years. Eur J Orthod. 1983;5:1-46.

23. Jacob HB, Buschang $\mathrm{PH}$. Vertical craniofacial growth changes in French-Canadians between 10 and 15 years of age. Am J Orthod Dentofacial Orthop. 2011;139:797-805.

24. Harris EF, Johnson MG. Heritability of craniometric and occlusal variables: a longitudinal sib analysis. Am J Orthod Dentofacial Orthop. 1991;99:258-268. 
25. Fudalej P, Kokich VG, Leroux B. Determining the cessation of vertical growth of the craniofacial structures to facilitate placement of single-tooth implants. Am J Orthod Dentofacial Orthop. 2007;131:S59-S67.

26. Aarts BE, Convens J, Bronkhorst EM, Kuijpers-Jagtman AM, Fudalej PS. Cessation of facial growth in subjects with short, average, and long facial types implications for the timing of implant placement. J Craniomaxillofac Surg. 2015;43:2106-2111.

27. Bjork A. Variations in the growth pattern of the human mandible: longitudinal radiographic study by the implant method. J Dent Res. 1963;42:400-411.

28. Pam A, Kemker SS, Ross CA, Golden R. The "equal environments assumption" in MZ-DZ twin comparisons: an untenable premise of psychiatric genetics? Acta Genet Med Gemellol (Roma). 1996;45:349-60.

29. Lundström A, McWilliam J. The influence of heredity and environment on six variables describing incisor orientation. Eur J Orthod. 1986;8:259-264.

30. Ichinose M, Nakasima A, Hu JR. Growth-related changes in familial resemblance of maxillofacial morphology. J Craniofac Genet Dev Biol. 1993;13:35-46.

31. Sidlauskiene M, Smailiene D, Lopatiene K, et al. Relationships between malocclusion, body posture, and nasopharyngeal pathology in pre-orthodontic children. Med Sci Monit. 2015;21:1765-1773.

32. Mossey PA. The heritability of malocclusion: part 2. The influence of genetics in malocclusion. Br J Orthod. 1999;26:195-203.

33. Amini F, Borzabadi-Farahani A. Heritability of dental and skeletal cephalometric variables in monozygous and dizygous Iranian twins. Orthod Waves 2009;68:72-79.

34. Djordjevic J, Jadallah M, Zhurov AI, Toma AM, Richmond S. Three-dimensional analysis of facial shape and symmetry in twins using laser surface scanning. Orthod Craniofac Res. 2013;16:146-160. 
35. Lobb WK. Craniofacial morphology and occlusal variation in monozygotic and dizygotic twins. Angle Orthod. 1987;57:219-233.

36. Carels C, Van Cauwenberghe N, Savoye I, et al. A quantitative genetic study of cephalometric variables in twins. Clin Orthod Res. 2001;4:130-140.

37. Toma AM. Characterization of normal facial features and their association with genes. Doctoral dissertation, Cardiff University, Cardiff; 2014.

38. Arat ZM, Rübendüz M, Akgül $A A$. The displacement of craniofacial reference landmarks during puberty: a comparison of three superimposition methods. Angle Orthod. 2003;73:374-380.

42. Arat ZM, Türkkahraman H, English JD, Gallerano RL, Boley JC. Longitudinal growth changes of the cranial base from puberty to adulthood. A comparison of different superimposition methods. Angle Orthod. 2010;80:537-544.

39. Lenza MA, Carvalho AA, Lenza EB, Lenza MG, Torres HM, Souza JB. Radiographic evaluation of orthodontic treatment by means of four different cephalometric superimposition methods. Dental Press J Orthod. 2015;20:29-36.

43. Baumrind S, Miller D, Molthen R. The reliability of head film measurements. 3. Tracing superimposition. Am J Orthod. 1976;70:617-644.

44. Lundstrom A, Woodside DG. Individual variation in growth directions expressed at the chin and the midface. Eur J Orthod. 1980;2:65-79.

45. Gliddon MJ, Xia JJ, Gateno J, Wong HTF, et al. The accuracy of cephalometric tracing superimposition. J Oral Maxillofac Surg. 2006;64:194-202.

41. Nielsen IL. Maxillary superimposition: a comparison of three methods for cephalometric evaluation of growth and treatment change. Am J Orthod Dentofacial Orthop. 1989;95:422-31. 
40. Ghafari J, Engel FE, Laster LL. Cephalometric superimposition on the cranial base: a review and a comparison of four methods. Am J Orthod Dentofacial Orthop. 1987;91:40313.

46. Katsadouris A, Halazonetis DJ. Geometric morphometric analysis of craniofacial growth between the ages of 12 and 14 in normal humans. Eur J Orthod. 2017;39:386-394.

47. Cakan DG, Ulkur F, Taner TU. The genetic basis of facial skeletal characteristics and its relation with orthodontics. Eur J Dent. 2012;6:340-345.

48. Corruccini RS, Sharma K, Potter RHY. Comparative genetic variance and heritability of dental occlusal variables in U.S. and northwest Indian twins. Am J Phys Anthropol. 1986;70:293-299. 
FIGURE 1 Cephalometric measurements used in this study: A, SN-NL (sella-nasion to nasal line, in degrees); B, ML-NL (nasal line to mandibular line, in degrees); C, SN-ML (sella-nasion to mandibular line, in degrees); D, y-axis (sella-nasion to sella-gnathion, in degrees); E, $\mathrm{PFH} / \mathrm{AFH}$ (posterior face height to anterior face height, in percent); and LAFH/AFH (lower anterior face height to anterior face height, in percent).

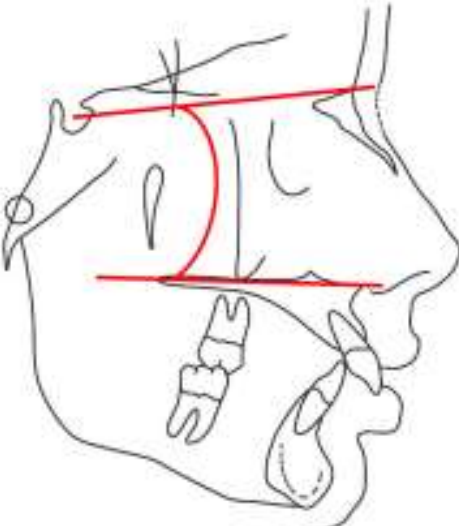

$\mathrm{SN}-\overline{\mathrm{NL}}$

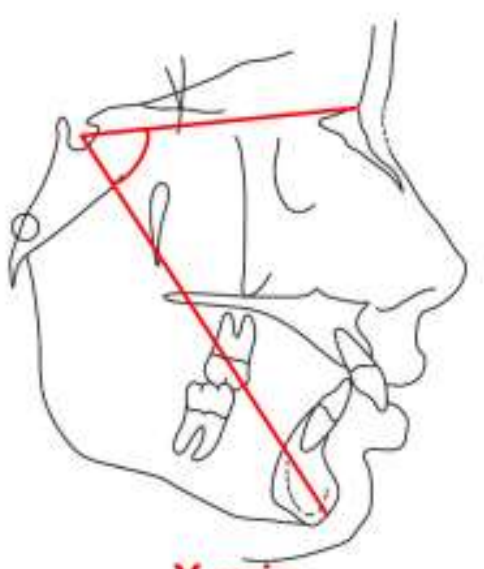

Y-axis

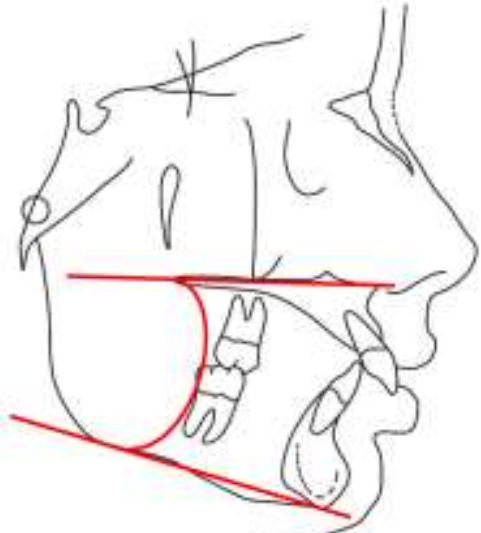

ML-NL

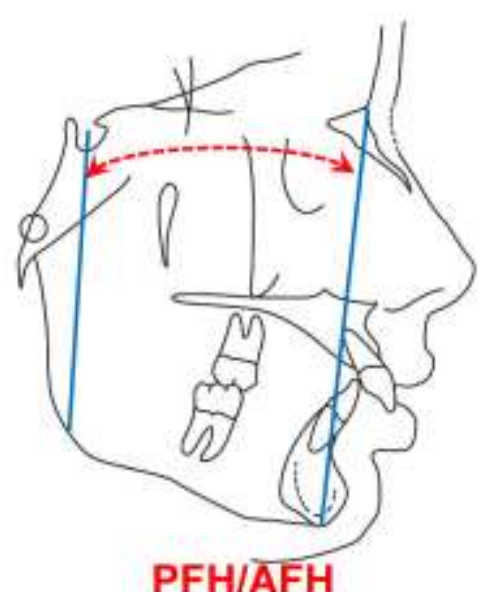

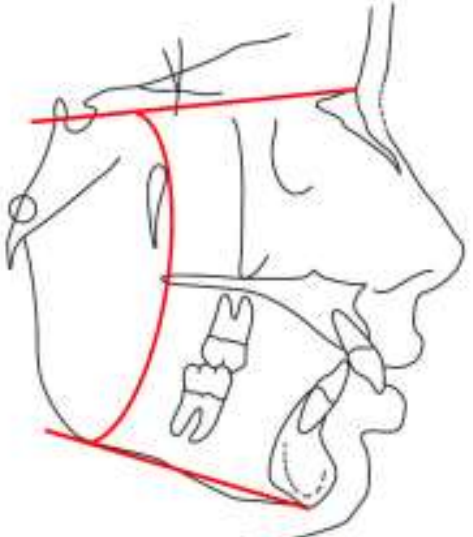

SN-ML

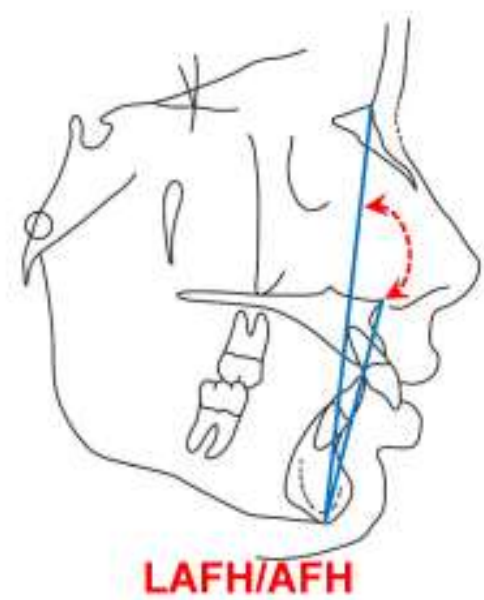


FIGURE 2 Predictive curves of the fitted model for (a) SN-NL angle, (b) ML-NL angle, (c) SN-ML angle, (d) y-axis angle, (e) PFH/AFH percentage, and (f) LAFH/AFH percentage incorporating both fixed and random effects.
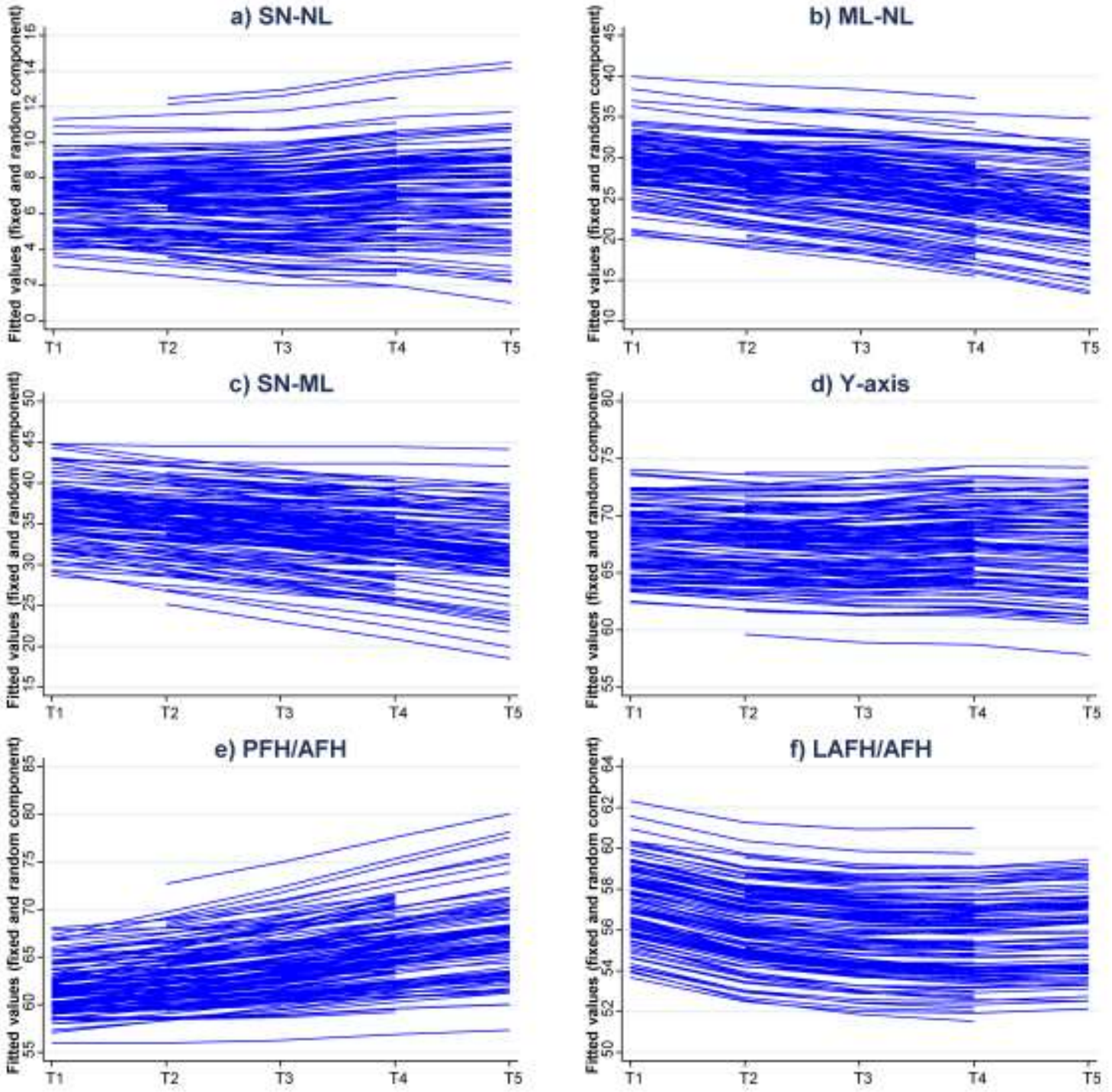
Tables

TABLE 1 Characteristics of the included patients through the follow-up period

\begin{tabular}{|c|c|c|c|c|}
\hline & & Values & t each & epoint \\
\hline & Time & Patients & Mean & SD \\
\hline \multirow{5}{*}{ SN-NL } & $\mathrm{T} 1$ & 103 & 6.96 & 3.77 \\
\hline & T2 & 130 & 6.84 & 2.59 \\
\hline & T3 & 131 & 6.70 & 2.74 \\
\hline & T4 & 128 & 7.08 & 3.23 \\
\hline & T5 & 85 & 7.18 & 2.90 \\
\hline \multirow{6}{*}{ ML-NL } & & & & \\
\hline & $\mathrm{T} 1$ & 103 & 29.24 & 4.26 \\
\hline & T2 & 130 & 27.82 & 4.46 \\
\hline & T3 & 131 & 26.80 & 4.71 \\
\hline & T4 & 128 & 25.27 & 5.08 \\
\hline & T5 & 85 & 23.85 & 5.10 \\
\hline \multirow{5}{*}{ SN-ML } & T1 & 103 & 36.73 & 4.38 \\
\hline & T2 & 130 & 35.38 & 4.15 \\
\hline & T3 & 131 & 34.24 & 4.52 \\
\hline & $\mathrm{T} 4$ & 128 & 33.13 & 4.78 \\
\hline & T5 & 85 & 31.87 & 5.19 \\
\hline \multirow{5}{*}{ Y-axis } & $\mathrm{T1}$ & 103 & 67.7 & 3.47 \\
\hline & T2 & 130 & 67.4 & 3.20 \\
\hline & T3 & 131 & 67.2 & 3.43 \\
\hline & $\mathrm{T} 4$ & 128 & 67.5 & 3.68 \\
\hline & T5 & 86 & 67.2 & 3.71 \\
\hline \multirow{5}{*}{$\mathrm{PFH} / \mathrm{AFH}$} & T1 & 103 & 61.72 & 3.41 \\
\hline & T2 & 130 & 62.86 & 3.39 \\
\hline & T3 & 131 & 64.08 & 3.78 \\
\hline & T4 & 128 & 65.78 & 3.99 \\
\hline & T5 & 85 & 67.09 & 4.53 \\
\hline \multirow{5}{*}{$\mathrm{LAFH} / \mathrm{AFH}$} & T1 & 103 & 57.40 & 2.45 \\
\hline & T2 & 130 & 56.31 & 2.31 \\
\hline & T3 & 131 & 55.84 & 2.33 \\
\hline & $\mathrm{T} 4$ & 128 & 55.70 & 2.30 \\
\hline & T5 & 85 & 55.89 & 2.05 \\
\hline
\end{tabular}

$\mathrm{n}$, patients; SD, standard deviation 
ABLE 2 Results of regression modeling for each outcome

\begin{tabular}{|c|c|c|c|c|c|c|c|}
\hline Outcome & Factor & Level & b & $95 \% \mathrm{Cl}$ & $P$ value & $\begin{array}{l}\text { Interaction } \\
\text { Gender`Time }\end{array}$ & $\begin{array}{l}\text { Interaction } \\
\text { Zygosity*Time }\end{array}$ \\
\hline \multirow{9}{*}{ SN-NL } & Time & T1 & Reference & & & - & - \\
\hline & & T2 & -0.11 & $-0.64,0.41$ & 0.67 & & \\
\hline & & T3 & -0.25 & $-0.80,0.30$ & 0.38 & & \\
\hline & & T4 & 0.13 & $-0.46,0.73$ & 0.66 & & \\
\hline & & T5 & 0.16 & $-0.56,0.88$ & 0.67 & & \\
\hline & Gender & Female & Reference & & & & \\
\hline & & Male & -1.70 & $-2.48,-0.92$ & $<0.001$ & & \\
\hline & Zygosity & $\mathrm{MZ}$ & Reference & & & & \\
\hline & & $\mathrm{DZ}$ & -0.93 & $-1.75,-0.11$ & 0.03 & & \\
\hline \multirow{9}{*}{ ML-NL } & Time & T1 & Reference & & & - & $P<0.05$ \\
\hline & & T2 & -1.15 & $-1.76,-0.54$ & $<0.001$ & & \\
\hline & & T3 & -1.89 & $-2.63,-1.14$ & $<0.001$ & & \\
\hline & & T4 & -3.06 & $-3.99,-2.13$ & $<0.001$ & & \\
\hline & & T5 & -4.37 & $-5.54,-3.20$ & $<0.001$ & & \\
\hline & Gender & Female & Reference & & & & \\
\hline & & Male & 1.05 & $-0.38,2.48$ & 0.15 & & \\
\hline & Zygosity & $\mathrm{MZ}$ & Reference & & & & \\
\hline & & $\mathrm{DZ}$ & 0.48 & $-1.07,2.02$ & 0.55 & & \\
\hline \multirow{9}{*}{ SN-ML } & Time & $\mathrm{T} 1$ & Reference & & & $P<0.05$ & - \\
\hline & & T2 & -1.01 & $-1.53,-0.49$ & $<0.001$ & & \\
\hline & & T3 & -1.85 & $-2.52,-1.18$ & $<0.001$ & & \\
\hline & & T4 & -2.61 & $-3.48,-1.74$ & $<0.001$ & & \\
\hline & & T5 & -3.65 & $-4.78,-2.52$ & $<0.001$ & & \\
\hline & Gender & Female & Reference & & & & \\
\hline & & Male & 0.01 & $-1.50,1.52$ & 0.99 & & \\
\hline & Zygosity & MZ & Reference & & & & \\
\hline & & $\mathrm{DZ}$ & 0.05 & $-1.39,1.50$ & 0.94 & & \\
\hline \multirow{9}{*}{ Y-axis } & Time & T1 & Reference & & & - & - \\
\hline & & T2 & -0.28 & $-0.69,0.12$ & 0.17 & & \\
\hline & & T3 & -0.39 & $-0.89,0.11$ & 0.13 & & \\
\hline & & T4 & 0.02 & $-0.61,0.64$ & 0.96 & & \\
\hline & & T5 & -0.25 & $-1.04,0.54$ & 0.54 & & \\
\hline & Gender & Female & Reference & & & & \\
\hline & & Male & -1.41 & $-2.49,-0.33$ & 0.01 & & \\
\hline & Zygosity & $\mathrm{MZ}$ & Reference & & & & \\
\hline & & $\mathrm{DZ}$ & -0.16 & $-1.30,0.98$ & 0.79 & & \\
\hline \multirow{9}{*}{ PFH/AFH } & Time & T1 & Reference & & & $P<0.05$ & - \\
\hline & & T2 & 0.75 & $0.26,1.23$ & 0.003 & & \\
\hline & & T3 & 1.69 & $1.06,2.33$ & $<0.001$ & & \\
\hline & & T4 & 3.02 & $2.19,3.85$ & $<0.001$ & & \\
\hline & & T5 & 4.14 & $3.06,5.23$ & $<0.001$ & & \\
\hline & Gender & Female & Reference & & & & \\
\hline & & Male & -0.06 & $-1.27,1.14$ & 0.92 & & \\
\hline & Zygosity & $M Z$ & Reference & & & & \\
\hline & & $\mathrm{DZ}$ & 0.35 & $-0.80,1.50$ & 0.55 & & \\
\hline \multirow{5}{*}{ LAFH/AFH } & Time & T1 & Reference & & & - & - \\
\hline & & T2 & -1.21 & $-1.54,-0.89$ & $<0.001$ & & \\
\hline & & T3 & -1.71 & $-2.05,-1.37$ & $<0.001$ & & \\
\hline & & T4 & -1.82 & $-2.18,-1.46$ & $<0.001$ & & \\
\hline & & T5 & -1.65 & $-2.08,-1.22$ & $<0.001$ & & \\
\hline
\end{tabular}




\begin{tabular}{|l|l|l|l|l|l|l|l|}
\hline \multirow{7}{*}{} & Gender & Female & Reference & & & & \\
\cline { 2 - 8 } & & Male & 0.51 & $-0.16,1.17$ & 0.14 & & \\
\cline { 2 - 8 } & Zygosity & MZ & Reference & & & & \\
\cline { 2 - 8 } & & DZ & $\mathbf{- 1 . 4 8}$ & $\mathbf{- 2 . 1 5 , - 0 . 8 2}$ & $<\mathbf{0 . 0 0 1}$ & & \\
\hline
\end{tabular}

b, unstandardized regression coefficient; $\mathrm{Cl}$, confidence interval; DZ, dizygotic; MZ, monozygotic.

Bold values indicate statistically significant effects at $5 \%$. 
TABLE 3 Concordance between each pair of twins for each outcome at T5 given as ICC (95\% CI)

\begin{tabular}{|c|c|c|c|c|c|c|}
\hline & Overall & \multicolumn{2}{|c|}{ Gender } & \multicolumn{2}{|c|}{ Zygosity } & \\
\hline Outcome & & Female & Male & $M Z$ & $\mathrm{DZ}$ & Heritability \\
\hline SN-NL & $\begin{array}{l}0.58 \\
(0.38,0.76)\end{array}$ & $\begin{array}{l}0.83 \\
(0.62,0.95)\end{array}$ & $\begin{array}{l}0.46 \\
(0.19,0.75)\end{array}$ & $\begin{array}{l}0.65 \\
(0.40,0.85)\end{array}$ & $\begin{array}{l}0.47 \\
(0.18,0.78)\end{array}$ & $34 \%$ \\
\hline ML-NL & $\begin{array}{l}0.60 \\
(0.40,0.77)\end{array}$ & $\begin{array}{l}0.68 \\
(0.34,0.91)\end{array}$ & $\begin{array}{l}0.85 \\
(0.71,0.93)\end{array}$ & $\begin{array}{l}0.83 \\
(0.67,0.93)\end{array}$ & $\begin{array}{l}0.40 \\
(0.12,0.76)\end{array}$ & $72 \%$ \\
\hline SN-ML & $\begin{array}{l}0.65 \\
(0.47,0.81)\end{array}$ & $\begin{array}{l}0.84 \\
(0.64,0.95)\end{array}$ & $\begin{array}{l}0.81 \\
(0.64,0.91)\end{array}$ & $\begin{array}{l}0.85 \\
(0.71,0.94)\end{array}$ & $\begin{array}{l}0.54 \\
(0.25,0.81)\end{array}$ & $67 \%$ \\
\hline Y-axis & $\begin{array}{l}0.63 \\
(0.44,0.80)\end{array}$ & $\begin{array}{l}0.77 \\
(0.49,0.93)\end{array}$ & $\begin{array}{l}0.80 \\
(0.62,0.91)\end{array}$ & $\begin{array}{l}0.85 \\
(0.70,0.93)\end{array}$ & $\begin{array}{l}0.47 \\
(0.17,0.79)\end{array}$ & $72 \%$ \\
\hline $\mathrm{PFH} / \mathrm{AFH}$ & $\begin{array}{l}0.66 \\
(0.49,0.81)\end{array}$ & $\begin{array}{l}0.82 \\
(0.59,0.94)\end{array}$ & $\begin{array}{l}0.81 \\
(0.64,0.92)\end{array}$ & $\begin{array}{l}0.85 \\
(0.71,0.94)\end{array}$ & $\begin{array}{l}0.56 \\
(0.27,0.82)\end{array}$ & $66 \%$ \\
\hline LAFH/AFH & $\begin{array}{l}0.51 \\
(0.30,0.72)\end{array}$ & $\begin{array}{l}0.03 \\
\text { (NC) }\end{array}$ & $\begin{array}{l}0.81 \\
(0.64,0.92)\end{array}$ & $\begin{array}{l}0.83 \\
(0.68,0.93)\end{array}$ & $\begin{array}{l}0.19 \\
(0.01,0.75)\end{array}$ & $79 \%$ \\
\hline
\end{tabular}

ICC, intraclass correlation coefficient; $\mathrm{Cl}$, confidence interval; DZ, dizygotic; MZ, monozygotic. 


\section{Supplementary material}

TABLE S1. Results of stratified regression modeling for each outcome that had significant interactions of gender with time in Table III

\begin{tabular}{|c|c|c|c|c|c|c|c|c|}
\hline & & & \multicolumn{3}{|c|}{ Female } & \multicolumn{3}{|c|}{ Male } \\
\hline Outcome & Factor & Level & $\mathbf{b}$ & $95 \% \mathrm{Cl}$ & $P$ value & $\mathbf{b}$ & $95 \% \mathrm{Cl}$ & $P$ value \\
\hline \multirow{7}{*}{ SN-ML } & Time & T1 & Reference & & & & & \\
\hline & & $\mathrm{T} 2$ & -1.38 & $-2.13,-0.64$ & $<0.001$ & -1.30 & $-1.91,-0.69$ & $<0.001$ \\
\hline & & T3 & -2.51 & $-3.35,-1.67$ & $<0.001$ & -2.51 & $-3.23,-1.80$ & $<0.001$ \\
\hline & & T4 & -3.15 & $-4.13,-2.17$ & $<0.001$ & -3.92 & $-4.79,-3.04$ & $<0.001$ \\
\hline & & T5 & -4.19 & $-5.44,-2.94$ & $<0.001$ & -5.49 & $-6.59,-4.39$ & $<0.001$ \\
\hline & Zygosity & $\mathrm{MZ}$ & Reference & & & & & \\
\hline & & DZ & -0.24 & $-2.44,1.95$ & 0.83 & 0.14 & $-1.74,2.01$ & 0.89 \\
\hline \multirow{7}{*}{ PFH/AFH } & Time & T1 & Reference & & & & & \\
\hline & & T2 & 1.08 & $0.41,1.75$ & 0.002 & 1.00 & $0.41,1.59$ & 0.001 \\
\hline & & T3 & 2.31 & $1.57,3.06$ & $<0.001$ & 2.26 & $1.56,2.96$ & $<0.001$ \\
\hline & & T4 & 3.63 & $2.77,4.50$ & $<0.001$ & 4.10 & $3.25,4.96$ & $<0.001$ \\
\hline & & T5 & 4.38 & $3.28,5.48$ & $<0.001$ & 5.89 & $4.82,6.96$ & $<0.001$ \\
\hline & Zygosity & $\mathrm{MZ}$ & Reference & & & & & \\
\hline & & DZ & 0.53 & $-1.25,2.32$ & 0.56 & 0.38 & $-1.08,1.84$ & 0.61 \\
\hline
\end{tabular}

b, unstandardized regression coefficient; $\mathrm{Cl}$, confidence interval; $\mathrm{DZ}$, dizygotic; $\mathrm{MZ}$, monozygotic.

Bold values indicate statistically significant effects at $5 \%$. 
TABLE S2 Results of stratified regression modeling for each outcome that had significant interactions of zygosity with time in Table III.

\begin{tabular}{|c|c|c|c|c|c|c|c|c|}
\hline 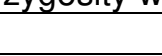 & 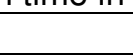 & 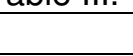 & \multicolumn{3}{|c|}{ Monozygotic } & \multicolumn{3}{|c|}{ Dizygotic } \\
\hline Outcome & Factor & Level & b & $95 \% \mathrm{Cl}$ & $P$ value & b & $95 \% \mathrm{Cl}$ & $P$ value \\
\hline \multirow{7}{*}{ ML-NL } & Time & T1 & Reference & & & & & \\
\hline & & T2 & -0.73 & $-1.46,0$ & 0.05 & -2.15 & $-3.04,-1.26$ & $<0.001$ \\
\hline & & T3 & -1.69 & $-2.51,-0.87$ & $<0.001$ & -3.19 & $-4.14,-2.23$ & $<0.001$ \\
\hline & & T4 & -2.95 & $-3.92,-1.99$ & $<0.001$ & -4.82 & $-5.89,-3.76$ & $<0.001$ \\
\hline & & T5 & -4.09 & $-5.29,-2.89$ & $<0.001$ & -6.84 & $-8.16,-5.52$ & $<0.001$ \\
\hline & Gender & Female & Reference & & & & & \\
\hline & & Male & 0.75 & $-0.92,2.42$ & 0.38 & 1.34 & $-0.96,3.63$ & 0.25 \\
\hline
\end{tabular}

b, unstandardized regression coefficient; $\mathrm{Cl}$, confidence interval; $\mathrm{DZ}$, dizygotic; $\mathrm{MZ}$, monozygotic.

Bold values indicate statistically significant effects at $5 \%$. 
TABLE S3 Concordance between each pair of twins for each outcome at T4 given as ICC (95\% CI)

\begin{tabular}{|c|c|c|c|c|c|c|}
\hline & Overall & Gender & & Zygosity & & \\
\hline Outcome & & Female & Male & MZ & DZ & Heritability \\
\hline SN-NL & $\begin{array}{l}0.49 \\
(0.31,0.67)\end{array}$ & $\begin{array}{l}0.60 \\
(0.33,0.83)\end{array}$ & $\begin{array}{l}0.30 \\
(0.07,0.68)\end{array}$ & $\begin{array}{l}0.58 \\
(0.36,0.78)\end{array}$ & $\begin{array}{l}0.39 \\
(0.14,0.69)\end{array}$ & $31 \%$ \\
\hline ML-NL & $\begin{array}{l}0.31 \\
(0.14,0.55)\end{array}$ & $\begin{array}{l}0.31 \\
(0.03,0.81)\end{array}$ & $\begin{array}{l}0.77 \\
(0.61,0.88)\end{array}$ & $\begin{array}{l}0.72 \\
(0.53,0.86)\end{array}$ & $\begin{array}{l}0.09 \\
(0,0.73)\end{array}$ & $69 \%$ \\
\hline SN-ML & $\begin{array}{l}0.50 \\
(0.33,0.68)\end{array}$ & $\begin{array}{l}0.56 \\
(0.26,0.82)\end{array}$ & $\begin{array}{l}0.77 \\
(0.61,0.88)\end{array}$ & $\begin{array}{l}0.75 \\
(0.58,0.88)\end{array}$ & $\begin{array}{l}0.37 \\
(0.14,0.67)\end{array}$ & $60 \%$ \\
\hline Y-axis & $\begin{array}{l}0.46 \\
(0.28,0.66)\end{array}$ & $\begin{array}{l}0.49 \\
(0.18,0.80)\end{array}$ & $\begin{array}{l}0.69 \\
(0.49,0.84)\end{array}$ & $\begin{array}{l}0.76 \\
(0.59,0.88)\end{array}$ & $\begin{array}{l}0.28 \\
(0.06,0.66)\end{array}$ & $67 \%$ \\
\hline $\mathrm{PFH} / \mathrm{AFH}$ & $\begin{array}{l}0.53 \\
(0.36,0.70)\end{array}$ & $\begin{array}{l}0.56 \\
(0.27,0.83)\end{array}$ & $\begin{array}{l}0.76 \\
(0.60,0.88)\end{array}$ & $\begin{array}{l}0.75 \\
(0.57,0.88)\end{array}$ & $\begin{array}{l}0.39 \\
(0.16,0.67)\end{array}$ & $59 \%$ \\
\hline LAFH/AFH & $\begin{array}{l}0.42 \\
(0.24,0.62)\end{array}$ & $\begin{array}{l}0.24 \\
(0.02,0.72)\end{array}$ & $\begin{array}{l}0.62 \\
(0.41,0.80)\end{array}$ & $\begin{array}{l}0.71 \\
(0.52,0.85)\end{array}$ & $\begin{array}{l}0.06 \\
(0,0.91)\end{array}$ & $69 \%$ \\
\hline
\end{tabular}

ICC, intraclass correlation coefficient; $\mathrm{Cl}$, confidence interval; DZ, dizygotic; MZ, monozygotic. 
TABLE S4 Agreement between repeated measurements analysis of 50 lateral cephalograms.

\begin{tabular}{|l|l|l|}
\hline Variable & CCC (95\% Cl) & $\begin{array}{l}\text { Average Difference } \\
\mathbf{( 9 5 \% ~ L o A ) ~}\end{array}$ \\
\hline SN-NL & $0.964(0.945,0.984)$ & $-0.02(-0.81,0.78)$ \\
\hline NL-ML & $0.942(0.911,0.972)$ & $0.14(-1.37,1.66)$ \\
\hline SN-ML & $0.874(0.831,0.917)$ & $0.01(-1.64,1.66)$ \\
\hline Y-Axis & $0.935(0.903,0.967)$ & $0.06(-1.42,1.54)$ \\
\hline
\end{tabular}

CCC, concordance correlation coefficient; $\mathrm{Cl}$, confidence interval; LoA, limits of agreement. 